\title{
Goya y sus críticos (y otros ensayos)
}

\author{
GLENDINNING, Nigel
}

Ediciones Complutenses, Madrid, 2017

La repentina muerte de Nigel Glendinning el 23 de febrero del año 2013 frustró su proyecto de terminar de escribir y de publicar un nuevo estudio sobre el pintor Francisco de Goya. Su fallecimiento fue el motivo que ocasionó la reedición de, quizás, la obra más señalada de toda su producción historiográfica y también de las más influyentes en los estudios sobre el genial arista aragonés: Goya y sus críticos. Publicada en 1983 por la editorial Taurus, esta obra es la versión española de la original inglesa de 1977 que corrió a cargo de la Yale University Press. En la traducción española el autor quiso mejorar el texto, añadiendo nuevos datos y ampliando la bibliografía.

Cuarenta años después, al título de esta nueva edición de 2017 de Goya y sus críticos le sigue una apostilla: y otros estudios, reveladora de las novedades que esta ofrece. El texto original está precedido por dos esclarecedores estudios de las compañeras y amigas del hispanista: Sarah Symmons, Senior Lecturer en la University of Essex, y Jesusa Vega, catedrática de Historia del Arte de la Universidad Autónoma de Madrid. Esta última ha sido además la responsable de la publicación y la encargada de cuidar que esta se hiciera ajustándose en la medida de lo posible a la original española de 1983; sólo se han modificado algunos detalles que ayudan a agilizar su lectura.

Como ha señalado la profesora Vega, estos estudios introductorios tienen el objetivo de explicar lo que ha significado toda la actividad de Glendinning en los estudios del pintor. Ciertamente, sus trabajos marcaron un antes y un después en el conocimiento y la interpretación de la obra y de la figura de Goya; así podemos constatarlo con la lectura de la presentación que da comienzo a este nuevo libro y que corresponde a la laudatio escrita y pronunciada por el profesor Valeriano Bozal, catedrático de Historia del Arte de la Universidad Complutense, con motivo de la investidura como Doctor Honoris Causa de Nigel Glendinning en la citada universidad en el año 2006. Este texto, que en palabras de Jesusa Vega es «el mejor escrito de presentación del estudioso británico», aparece complementado con algunos

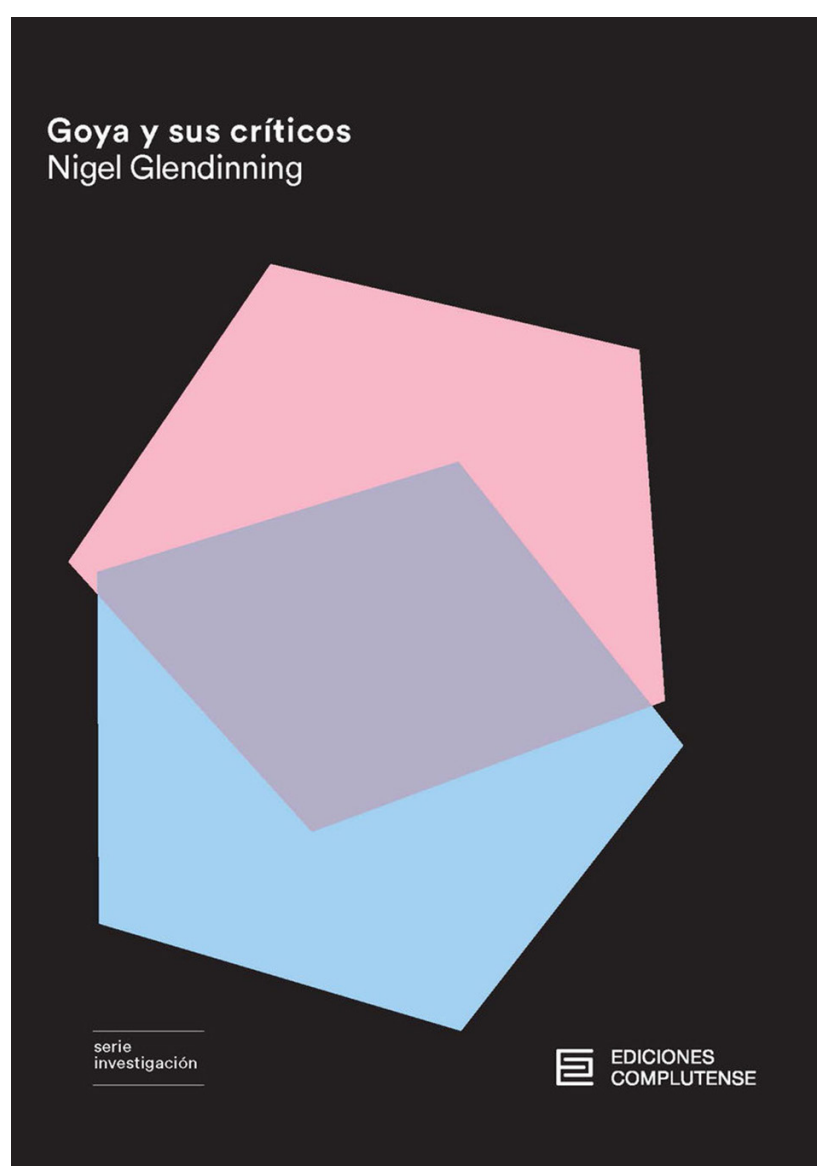

fragmentos de otra alocución que el profesor Bozal dedicó al hispanista con motivo de la concesión del Premio Fundación Amigos del Museo del Prado en 2005.

A lo largo de estos textos introductorios se percibe el cariño que sus autores, Bozal, Vega y Symmons, profesaban a Glendinning. Es bueno que se refleje en estas líneas la calidad humana del homenajeado, además de su rigor y solvencia investigadora, que es la razón principal por la que se reedita su obra; pero es importante no desechar el testimonio de gratitud que demuestran estos historiadores en las líneas que le dedican. 
La reedición de esta obra está justificada por dos motivos; en primer lugar dada la conveniencia de reeditar un texto que marcó un hito en los estudios sobre Goya y que sorprendentemente, no se había vuelto a publicar ni en su edición inglesa ni en la española. Por otro lado, Sarah Symmons y Jesusa Vega deseaban que la obra de Glendinning, su amigo y maestro, no quedara en el olvido, y fuera conocida por las nuevas generaciones de historiadores del arte.

Es conveniente recordar que Nigel Glendinning fue un entusiasta hispanista dedicado al estudio del siglo XVI-XVII. Inició su trayectoria investigadora abordando la literatura española de dicha centuria, especialmente la obra de José de Cadalso. Este bagaje fue esencial para su conocimiento de la cultura española y fue a través del citado literato que llegó a conocer al genial artista de Fuendetodos, que a partir de entonces, se convirtió en su objeto de investigación preferencial. Debemos resaltar que la formación literaria de Glendinning fue esencial para contextualizar adecuadamente el arte de Goya y profundizar en su comprensión. Como bien ha señalado la profesora Symmons en su estudio introductorio, la principal preocupación de este investigador fue desarrollar el vínculo entre el arte y la literatura españolas. Este enfoque tuvo su consecuente influencia sobre la historiografía artística posterior, además de en las exposiciones organizadas de la obra de Goya.

Goya y sus críticos puede definirse como una lúcida investigación acerca de la fortuna historiográfica desarrollada en torno a la obra de dicho artista y de su personalidad. El repaso comienza con sus coetáneos dieciochescos y finaliza con el análisis de la influencia del pintor sobre artistas del siglo XX: poetas, literatos, músicos y cineastas. Es un estudio de la leyenda de Goya a través del tiempo, de los hitos y de las contribuciones a su fortuna crítica. Esta revisión trazada por Glendinning demuestra cómo a través de la historiografía se ha ido conformando una imagen del pintor, adaptándola según las necesidades ideológicas requeridas en cada momento histórico, y en muchas ocasiones, absolutamente contrapuestas. Este hecho habla de la versatilidad de Goya y de la complejidad que reviste el estudio de su producción artística y de su persona. Tal y como se señala en el libro, hay casi tantas imágenes de Goya como estudiosos del mismo.

Es por esta razón que, tal y como demostró Glendinning, el historiador del arte debe estar capacitado para saber aplicar un método de análisis adecuado al objeto artístico.
El autor hablaban con toda razón y a sabiendas de que han sido muchas las interpretaciones dadas a la producción de Goya, muchas de ellas sin tomar en consideración el tiempo en el que vivió o la apasionada personalidad del pintor. Por todo ello, Glendinning expuso la necesidad de estudiarla desde una perspectiva amplia e interdisciplinar. No es un hecho baladí que citara al comienzo y al final del presente trabajo una lúcida reflexión del filósofo Ludwing Wittgenstein: «Cualquiera cosa que vemos podría ser distinta de lo que es. Cualquiera cosa que podamos describir podría ser otra cosa de la que es». Con estas pocas palabras el autor supo explicar su método de trabajo. Esta enseñanza debería tomarse en consideración por el historiador del arte, máxime cuando se trata de estudiar a artistas de la complejidad del maestro aragonés.

En relación al método de estudio que debemos aplicar los profesionales de la Historia del Arte, se encuentra la problemática que durante las últimas décadas ha afectado directamente a Francisco de Goya y al Ilamado "canon goyesco»; es el caso de las prácticas atribucionistas. Esta circunstancia preocupó especialmente a Glendining. La discusión en torno a la paternidad de pinturas tan destacadas como El coloso, La lechera de Burdeos o el Retrato de Marianito Goya fue seguida por él con preocupación. En su opinión, el fundamento de este polémico asunto no radicaba en el debate acerca de las copias y la intervención de Goya en las mismas, sino en su convencimiento acerca de que el atribucionismo reduce las obras de arte a mera mercancía. Por esta razón él mismo indicó que si Goya y sus críticos volviera a editarse, se le tendría que añadir un capitulo dedicado a este tema.

La profesora Vega tomó en consideración el deseo de su maestro y amigo y es por esto que para poner de manifiesto el devenir de la imagen de Goya y de su corpus, especialmente en el Museo del Prado, esta nueva edición de Goya y sus críticos se complemente con una contribución de Glendinning publicada en Goya 1900. Catálogo ilustrado y estudio de la Exposición en el Ministerio de Instrucción Pública: «El problema de las atribuciones desde la exposición de Goya de 1900».

En esta aportación se aprecia la opinión negativa del autor acerca de las tendencias atribucionistas y pone de relieve la mirada del historiador, por encima de otros enfoques técnicos. Igualmente, el abuso del expertizaje puede llegar a 
hacer peligrar la contextualización histórica de la producción de Goya, una de las grandes aportaciones de Glendinning a la historiografía artística. Los debates derivados de la autoría de las obras de Goya están plenamente justificados pues estos van siempre aparejados a la genialidad de los grandes maestros; pero es importante que la argumentación previa a la atribución sea suficientemente sólida.

En suma, debemos agradecer el regreso de esta obra que ya hace cuarenta años marcó un punto de inflexión en los estudios sobre Goya y sobre pintura española. Este influyente texto marcó un hito en su época y nos mostró no solo la evolución de las interpretaciones que ha tenido la obra de uno de los más geniales artistas de todos los tiempos, sino que nos ha enseñado cuál es el camino a seguir para desarrollar nuevas perspectivas sobre los estudios en Historia del Arte.

Carmen de-Tena-Ramírez 